See discussions, stats, and author profiles for this publication at: https://www.researchgate.net/publication/334208956

\title{
Risk Attitudes and Digit Ratio (2D:4D): Evidence From Prospect Theory
}

Article in SSRN Electronic Journal · January 2019

DOI: $10.2139 /$ ssrn. 3409084

7 authors, including:

C. Levent Neyse

German Institute for Economic Research

18 PUBLICATIONS 109 CITATIONS

SEE PROFILE

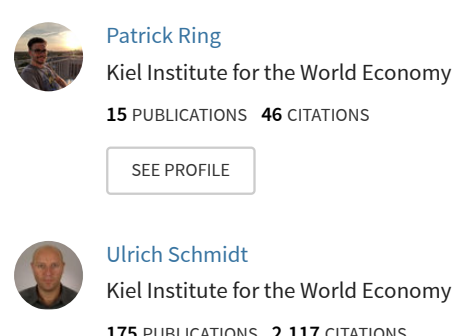

54 PUBLICATIONS 1,983 CITATIONS

175 PUBLICATIONS 2,117 CITATIONS

SEE PROFILE

SEE PROFILE 


\title{
Risk Attitudes and Digit Ratio (2D:4D): Evidence from Prospect Theory
}

\author{
Levent Neyse ${ }^{1,2}$, Ferdinand M. Vieider ${ }^{3}$, Patrick Ring ${ }^{1,}{ }^{*}$, Catharina Probst ${ }^{4}$, \\ Christian Kaernbach ${ }^{4}$, Thilo van Eimeren ${ }^{5}$, and Ulrich Schmidt ${ }^{1,4}$ \\ ${ }^{1}$ Kiel Institute for the World Economy, Germany \\ ${ }^{2}$ SOEP at DIW, Berlin, Germany \\ ${ }^{3}$ Department of Economics, Ghent University, Belgium \\ ${ }^{4}$ Kiel University, Germany \\ ${ }^{5}$ Cologne University Hospital, Germany \\ ${ }^{*}$ Corresponding author e-mail address: levent.neyse@ifw-kiel.de
}

\begin{abstract}
Prenatal androgens have organizational effects on brain and endocrine system development, which may have a partial impact on economic decisions. Numerous studies investigated the relationship between prenatal testosterone and financial risk taking, yet results remain inconclusive. We suspect that this is due to difficulty in capturing risk preferences with expected utility based tasks. Prospect theory, on the other hand, suggests that risk preferences differ between gains, losses and mixed prospects, as well as for different probability levels. This study investigates the relationship between financial risk taking and 2D:4D, a putative marker of prenatal testosterone exposure, in the framework of prospect theory. We conducted our study with 350 participants from Caucasian and Asian ethnicities. We do not observe any significant relationship between 2D:4D and risk taking in neither of these domains and ethnicities.
\end{abstract}

Keywords: Risk, Prospect Theory, Prenatal Testosterone, Digit Ratio 


\section{Introduction}

Prenatal testosterone exposure (PTE) has organizational effects on the brain and endocrine system development of the fetus and thereby it may have a systematic influence on subsequent behavior (see Manning, 2002, for a review). This relationship has attracted the interest of economists, who studied its role in various contexts including social preferences (Buser, 2012; Brañas-Garza et al., 2013), financial trading (Coates et al., 2009), competitive bidding (Pearson and Schipper, 2012) or manegarial activities (Guiso and Rustichini, 2018). Although studies investigating the association between risk aversion and 2D:4D have the largest proportion in this literature, the results are not conclusive. While several studies showed that higher PTE yields lower risk aversion, many others reported null results.

This study investigates the relationship between financial risk taking and PTE in the framework of prospect theory. According to prospect theory (Kahneman and Tversky, 1979; Tversky and Kahneman, 1992; Wakker, 2010a), risk preferences may differ between gains, losses and mixed prospects, as well as for different probability levels. In his recent study, Hermann (2017) showed that higher PTE correlates with lower degrees of loss aversion. This might suggest that the inconclusive results in the literature may be due to the domain-dependent nature of risk preferences. Evolutionary perspective confirms this argument as survival decisions such as foraging or reproduction involve risk taking both in gain and loss domains. As a result, prospect theory is now shaping foraging models as well (McDermott et al., 2008). We find no significant relationship between PTE and risk-aversion in neither domains. This null result is consistent both for Caucasian and Asian samples in our study.

\section{Background}

\section{D:4D and Prenatal Testosterone Exposure}

Unlike circulating testosterone, direct measure of PTE through saliva or blood samples is not possible as the exposure takes place during the first trimester of the pregnancy. This is why, the ratio between the lengths of the index and ring fingers (2D:4D or digit ratio) is employed as an indirect somatic marker of PTE (Goy and McEwen, 1980). A smaller 2D:4D is associated with higher PTE and men in general have lower ratios than 
women (Lutchmaya et al., 2004; Hönekopp and Watson, 2010).

The negative relationship between 2D:4D and PTE has been confirmed with various methods. Direct evidence from the amniotic fluid during pregnancy, Lutchmaya et al. (2004) and Ventura et al. (2013) showed a significant relationship between prenatal testosterone-estradiol ratio in utero and 2D:4D of infants and newborns. Male fetuses with Klinefelter's Syndrome are shown to have lower prenatal testosterone, therefore higher 2D:4D ratios (Manning et al., 2013). Fetuses with Congenital Adrenal Hyperplasia are exposed to higher levels of testosterone in utero, which yields lower 2D:4D ratios (Brown et al., 2002). Rodents that had been administered testosterone in utero ended up having lower 2D:4D ratios than rodents in a control group (Zheng and Cohn, 2011). van Anders et al. (2006) show that females with male twins have lower 2D:4D than the ones with female twins. Yet, it should be noted that there are also disputes about the connection between 2D:4D and prenatal androgen exposure (McIntyre, 2006).

\section{D:4D and Risk Aversion}

A number of studies suggested correlations between 2D:4D and economic behavior such as social preferences (Buser, 2012; Brañas-Garza et al., 2013; Galizzi and Nieboer, 2015), profitability in financial trading (Coates et al., 2009), reaction to payment scheme changes (Friedl et al., 2018), manegarial traits (Guiso and Rustichini, 2018) and overconfidence (Neyse et al., 2016; Dalton and Ghosal, 2018). In the context of risk taking, several studies reported positive correlations between 2D:4D (lower PTE) and risk aversion, although a larger proportion reported null findings (See Table 1 for an overview of the literature). Despite significant results in the literature, frequently obtained nullresults, Type I errors due to small sample sizes and varying gender specific findings suggest that the relationship between $2 \mathrm{D}: 4 \mathrm{D}$ and risk taking is difficult to capture. ${ }^{1}$ Further heterogeneities, such as ethnicities in the samples or the hands used for the 2D:4D analysis, makes the interpretation of the results even more challenging.

Brañas-Garza et al. (2018) tested the relationship with the largest sample in the literature to this date $(\mathrm{N}=702)$. Their results show a positive correlation between 2D:4D and revealed risk aversion in the incentivized Eckel and Grossman task (Eckel and Grossman, 2008). They, however, do not obtain a significant result with the self reported risk attitude question. This contradiction within the same study mimics diverse findings in

\footnotetext{
${ }^{1}$ See Parslow et al. (2018) for an extensive review of 2D:4D and risk taking literature.
} 
the literature. One may suggests that a potential reason behind inconsistent findings might be the variations in the risk eliciation methods. However, replicability issue is common even among studies that employ the same tasks.

Table 1: Literature on 2D:4D and risk taking

\begin{tabular}{lccccc}
\hline Study & Task & N & Hands & Ethnicities & Result \\
\hline Brañas-Garza et al. (2018) & & & & & \\
Measure I & EG $(\$)$ & 702 & Both & Mix & $(-)$ \\
Measure II & Survey & 702 & Both & Mix & NS \\
Lima de Miranda et al. (2018) & EG $(\$)$ & 150 & Both & Caucasian & NS \\
Alonso et al. (2018) & HL $(\$)$ & 497 & Right & Mix & NS \\
Parslow et al. (2018) & MPL $(\$)$ & 330 & Both & Mix & NS \\
Chicaiza-Becerra and Garcia-Molina (2017) & EG $(\$)$ & 123 & Both & Ladino & NS (R) / (-)(L) \\
Barel (2017) & Survey & 204 & Both & Caucasian & NS \\
Bönte et al. (2016) & Survey & 432 & Right & Caucasuan & NS \\
Schipper (2012) & HL $(\$)$ & 208 & Right & Mix & NS \\
Drichoutis and Nayga (2015) & HL $(\$)$ & 157 & Right & Caucasian & NS \\
Aycinena et al. (2014) & HL $(\$)$ & 219 & Both & Ladino & NS \\
Stenstrom et al. (2011) & Survey & 413 & Right & Caucasian & NS (W) / (-)(M) \\
Garbarino et al. (2011) & MPL $(\$)$ & 152 & Mean & Caucasian & $(-)$ \\
Brañas-Garza and Rustichini (2011) & HL & 188 & Right & Caucasian & $(-)$ \\
Ronay and Von Hippel (2010) & GART $(\$)$ & 52 & Mean & Caucasian & $(-)($ M $)$ \\
Sapienza et al. (2009) $(\$)$ & 152 & Both & Caucasian & $(-)$ \\
Apicella et al. (2008) & HL $(\$)$ & 183 & Mean & Mix & NS \\
Dreber and Hoffman (2007) & Goth & Mix & NS \\
\hline \hline
\end{tabular}

Tasks that used monetary incentives are shown with $\$$. Right hands are shown with $\mathrm{R}$ and left with L.

Men are shown with M and women with W. NS represents non-significant results.

$(-)$ and $(+)$ presents the direction of the relationship between 2D:4D and risk-seeking in the tasks.

Task abbrevations are EG: Eckel and Grossman; HL: Holt and Laury; Survey: Self Reported; GP: Gneezy and Potters

Similar to Brañas-Garza et al. (2018), Lima de Miranda et al. (2018) and ChicaizaBecerra and Garcia-Molina (2017) used the incentivized Eckel and Grossman task. Yet, they did not observe any significant relationship between risk aversion and 2D:4D. ${ }^{2}$ The recent study of Parslow et al. (2018) which uses an extended and incentivized version of the task reports also null results from a large sample of women. In the case of self reported risk elicitation, Stenstrom et al. (2011) showed a positive correlation between

\footnotetext{
${ }^{2}$ Note that, despite the fact that right hand $2 \mathrm{D}: 4 \mathrm{D}$ is the most common measure in the literature, Chicaiza-Becerra and Garcia-Molina (2017) observe a significant positive correlation between 2D:4D and risk aversion only from left hands.
} 
financial risk-aversion and 2D:4D in men, while Brañas-Garza et al. (2018) did not observe a significant association. Holt and Laury method (Holt and Laury, 2002) generates a similar discrepancy. Studies using the Holt and Laury task with real monetary incentives (Sapienza et al., 2009; Schipper, 2012; Aycinena et al., 2014; Drichoutis and Nayga, 2015; Alonso et al., 2018) do not report any significant correlations, while Brañas-Garza and Rustichini (2011) reports that males with higher 2D:4D were more risk averse under unicentivized version of it. ${ }^{3}$ Finally, the Gneezy and Potters method (Gneezy and Potters, 1997) also produced conflicting results: High 2D:4D is associated with higher risk aversion in Dreber and Hoffman (2007) while Apicella et al. (2008) could not show any significant relationship.

\section{D:4D and Prospect Theory}

One potential reason behind contradicting results in the literature may be the fact that previously used methods are unable to capture the complexity of risky decisions. Most of the above mentioned risk elicitation methods rely on expected utility theory and have been designed to elicit only one parameter measuring the degree of relative risk aversion. Risk preferences, however, are known to be far more complex than modeled in expected utility theory. A large number of violations of expected utility motivated the development of various alternative theories which are usually descriptively more accurate than expected utility. Nowadays, prospect theory (Kahneman and Tversky, 1979; Tversky and Kahneman, 1992; Wakker, 2010a) is the most prominent descriptive alternative to expected utility. Based on extensive empirical evidence, prospect theory proposes that (i) behavior differs in the gain and loss domains (reflection effect), (ii) individuals are more risk averse over prospects involving both gains and losses than in either pure outcome domain (loss aversion), and (iii) people tend to be relatively insensitive to variations of probabilities, leading to subjective probability distortions. The elicitation of risk preferences in previous 2D:4D studies could not address this complexity of risky decisions as in most cases only gains and/or 50\% probabilities were involved.

Recent findings of Hermann (2017) may indeed suggest that the association between 2D:4D and risk aversion may alter between gain and loss domains. Using an incentivized

\footnotetext{
${ }^{3}$ The fact that 2D:4D has no impact on the risk preferences elicited with the HL method is in some sense consistent with the meta study of Filippin and Crosetto (2016) which shows that under this method no significant gender differences can be observed.
} 
Gächter et al. (2007) method, he observed that right hand 2D:4D ratios of participants were positively correlated with their elicited loss aversion levels.

The literature on the evolutionary basis of risk preferences also supports prospect theory. According to risk-sensitive foraging theory, making complex trade-off calculations is vital for animals and hunter-gatherers (see Kacelnik and El Mouden, 2013; Houston et al., 1993 for reviews). Since their survival is constantly threatened by various factors such as predators, competitors, natural conditions or starvation, their risk calculations are not only in the gain domain (McDermott et al., 2008). Further research also showed that decision biases such as loss aversion, are observed even in animals (Chen et al., 2006; Lakshminarayanan et al., 2011).

The goal of the present paper is to comprehensively study the impact of $2 \mathrm{D}: 4 \mathrm{D}$ on the different facets of risk attitudes. We employ the method of Vieider et al. (2015), in which certainty equivalents for only gains, only losses, and for mixed gain-loss lotteries are elicited while systematically varying the probabilities. This procedure allows us to analyze whether 2D:4D is associated with (i) risk preferences in the domain of gains, (ii) risk preferences in the domain of losses, (iii) the degree of loss aversion, and (iv) probabilistic insensitivity. While our study is motivated by prospect theory, its statistical analyses are based on model-free tests. By just comparing certainty equivalents, our analysis is entirely non-parametric and valid for any theory which is based on standard definitions of risk aversion.

In order to control for possible effects of ethnicity on 2D:4D patterns (see Manning, 2002), we ran our experiment with two ethnic samples, a Caucasian sample from Germany and an Asian sample from Vietnam. We chose these two ethnicities to ensure that our results are comparable with previous studies. On the one hand, a large proportion of the literature report findings from Caucasian samples. In the mixed samples, on the other hand, the largest non-Caucasian ethnic groups were Asians.

\section{Theoretical Background}

To formalize decision-making under risk we consider a set of monetary outcomes $X$. A lottery $P$ assigns a real number $P(x)$ to each $x \in X$ such that $P(x) \geq 0 \quad \forall x \in X$ and $\sum_{x \in X} P(x)=1$. $\mathcal{P}$ denotes the set of all lotteries. We consider a binary preference 
relation $\succeq$ defined on $\mathcal{P}$ where $\succ$ indicates strict preference and $\sim$ indifference.

The certainty equivalent of a lottery $P$, denoted by $C E(P) \in X$, is defined by $C E(P) \sim P$. A decision maker is risk averse if $C E(P) \leq E(P) \quad \forall P \in \mathcal{P}$, where $E$ designates the expectation operator. Moreover, decision maker $A$ is more risk averse than decision maker $B$ if $C E_{A}(P) \leq C E_{B}(P) \quad \forall P \in \mathcal{P}$ (Pratt, 1964). Consequently, if lower 2D:4D leads to less risk aversion, 2D:4D and certainty equivalents should be negatively correlated. This is the basic hypothesis for the analyses in the present paper.

In expected utility theory (von Neumann and Morgenstern, 1944), preferences of the decision maker are represented by

$$
E U(P)=\sum_{x \in X} u(x) P(x),
$$

where $u$ is a monotonically increasing utility function. In expected utility theory the degree of risk aversion depends solely on the curvature of $u$, i.e., (a higher degree of) risk aversion is equivalent to a (more) concave $u$. Empirical applications often rely on the specification $u(x)=x^{\alpha}$ where $\alpha>0$ is the degree of relative risk aversion. The method of Holt and Laury (2002) which is employed in the majority of 2D:4D studies on risk aversion has been specifically designed to elicit the parameter $\alpha$.

Starting with the famous paradoxes of Allais (1953), a large body of evidence has shown that subjects often violate expected utility when choosing between risky lotteries. This research has revealed that risk attitudes are far more complex than modeled in expected utility theory and has motivated the development of alternative theories with superior descriptive performance. Prospect theory has nowadays become the most prominent of these alternatives (Dhami, 2016; Starmer, 2000a; Wakker, 2010b). In prospect theory, outcomes are evaluated relative to a reference point, with positive deviations from the reference point coded as gains and negative deviations as losses. Our $C E$ 's are explicitly designed in such a way as to fix the reference point to zero-a more detailed discussion of this design feature is provided in L'Haridon and Vieider (2018). The experiment is based solely on lotteries with two outcomes. We denote these outcomes by $x$ and $y$ such that $|x|>|y| \geq 0$. Now if $x$ and $y$ are either both gains or both losses the utility of lottery $P$ with $P(x):=p$ in prospect theory is given by

$$
P T(P)=w(p) v(x)+[1-w(p)] v(y) .
$$


Compared to expected utility, the evaluation of lotteries in prospect theory differs by two aspects:

(i) Outcomes in prospect theory are evaluated by a value function $v$ which satisfies diminishing sensitivity and loss aversion. Diminishing sensitivity means that the marginal value is decreasing if one moves further away from the reference point (i.e., zero) implying a concave (convex) value function in the gain (loss) domain. This assumption accommodates the reflection effect of Kahneman and Tversky (1979) which summarizes empirical evidence that people are typically risk averse (seeking) for gains (losses). Loss aversion indicates that a given loss has a higher impact on the attractiveness of a lottery than a gain of equal size and is captured by a value function which is steeper for losses than for gains. Numerous studies have provided an empirical basis for loss aversion on the behavioral level (Ganzach and Karsahi, 1995; Kahneman et al., 1990), the psychophysiological level (Hochman and Yechiam, 2011; Sokol-Hessner et al., 2009), the brain level (De Martino et al., 2010; Tom et al., 2007) and in self-reported feelings (McGraw et al., 2010).

(ii) Probabilities in prospect theory are transformed by a weighting function $w:[0,1] \rightarrow$ $[0,1]$ which is strictly increasing and satisfies $w(0)=0$ and $w(1)=1$. Originally, this value function was proposed to capture the tendency of people to overweight small and underweight large probabilities. Nowadays, there is ample evidence (Abdellaoui et al., 2011; Tversky and Fox, 1995; Wu and Gonzalez, 1996) that the weighting function is inverse-S shaped for most subjects, which implies, besides the overweighting (underweighting) of small (large) probabilities, a relative insensitivity towards probability changes for medium sized probabilities.

A central empirical finding in the context of prospect theory is the fourfold pattern of risk attitudes: People are risk averse for high probability gains and low probability losses while they are risk seeking for low probability gains and high probability losses (Kahneman and Tversky, 1979; Tversky and Kahneman, 1992). Evidence in favor of this pattern has been reported in several experimental studies (Cohen et al., 1987; Harbaugh et al., 2010; Tversky and Kahneman, 1992; Wehrung et al., 1989). Prospect theory directly implies the fourfold pattern if the influence of probability weighting is large relative to the curvature of the value function, e.g., if the value function is linear.

As mentioned in the introduction, our study is motivated by prospect theory. Therefore, we analyze pure gain, pure loss and mixed lotteries while systematically varying 
probabilities. However, our analysis does not rely on prospect theory or on any other theory and is entirely non-parametric. We just consider the certainty equivalent of a lottery $P$ and compare it to its expected value $(E(P))$. According to Pratt (1964), a subject is risk averse if $C E(P)<E(P)$, risk neutral if $C E(P)=E(P)$ and risk loving if $C E(P)>E(P)$. In the case of risk neutrality we thus have

$$
C E(P)=p x+(1-p) y
$$

Solving this equation for $p$ yields

$$
\frac{C E(P)-y}{x-y}=p
$$

In the following we will call $\left(C E_{i}-y_{i}\right) /\left(x_{i}-y_{i}\right)$ the normalized certainty equivalent of lottery $i$ denoted by $\pi_{i}$. The normalized certainty equivalent $\pi_{i}$ equals $p$ in the case of risk neutrality whereas it is less than (exceeds) $p$ in the case of risk aversion (seeking). For illustrative purposes, the analyses of the present paper will rely on normalized certainty equivalents instead of regular certainty equivalents. ${ }^{4}$ This has the advantage of making our measures directly comparable across outcomes, which is its great advantage in our setup. We can then further control for the effect of probabilities in our regression to detect variations in probabilistic sensitivity.

If we assume prospect theory with a linear value function, the normalized certainty equivalent equals the transformed probability, i.e. we get

$$
\pi_{i}=w(p)
$$

This equation shows that while the analysis of normalized certainty equivalents does not rely on prospect theory it allows a straightforward interpretation in terms of probability weights.

For our analysis based on normalized certainty equivalents we do not need to assume that risk attitudes do not change as stakes increase, since one can simply insert the outcome dimension into the regression to test this hypothesis. By regressing the index on the probability of winning or losing in the given prospect, one can then detect

\footnotetext{
${ }^{4}$ Since a higher regular certainty equivalent implies a higher normalized certainty equivalent, this procedure does not involve any assumptions or restrictions.
} 
probabilistic insensitivity, which will be captured by a regression coefficient smaller than unity, i.e. probability weights that change less than proportionally with the probability of winning or losing the prize.

In order to measure loss aversion without altering the reference point, we aimed at fixing the certainty equivalents to zero for mixed prospects (see L'Haridon and Vieider (2018) for details). In these cases, participants had to state a loss $y<0$ that makes them indifferent between playing a 50/50 lottery involving a certain gain $x>0$ and the stated loss $y$, or receiving zero for sure. Obviously, a higher degree of risk aversion corresponds to a lower absolute value of $y$. Instead of analyzing $y$ directly we consider the Gain-Loss Ratio (GLR)given by

$$
G L R=\frac{x}{-y}
$$

As $x$ is fixed, a higher GLR is equivalent to a higher degree of risk aversion. Again, our analysis relying on GLR is entirely non-parametric and does not rely on prospect theory. However, the GLR has a clear interpretation in this theory. For mixed gain-loss prospect prospect theory can be defined as as follows:

$$
P T(P)=w(p) v(x)+\lambda w(1-p) v(y)
$$

where $x>0>y$ and $\lambda$ is the index of loss aversion where values of $\lambda>1$ indicate loss aversion. In our design with 50/50 lotteries and a certainty equivalent of zero a linear value function yields $G L R=\lambda$. Therefore, GLR allows for a non-parametric analysis of risk aversion for mixed prospects and can be interpreted as index of loss aversion in the context of prospect theory.

\section{Materials and Methods}

\section{Participants}

The experimental sessions were run in Germany and Vietnam. In both samples sex ratios were balanced. The German sample consists 199 students from Kiel University, who were recruited with the hroot software (Bock et al., 2014). Students were randomly assigned to seats in a classroom. At the beginning of the experiment, participants were 
given general instructions about the experimental procedure, which were followed by the decision task. Subsequently, they were asked to fill out a short questionnaire. After the experiment, participants were invited one by one to a separate room for receiving their payments and scanning of their both hands. Due to missing information we used the data of 191 of the students.

In Vietnam, we ran the experiment with 243 students and the gender distribution was balanced. The students were recruited at the Economics University of Ho-Chi-Minh city using flyers. The hands of students were photocopied after the experiment. In our 2D:4D analysis, we used the data of 162 students due to quality issues in the copies and missing 2D:4D data from a part of the sample.

\section{Experimental Design}

We used the risk elicitation task of Vieider et al. (2015) in both countries. In this task, participants decide between binary monetary lotteries and different sure monetary payments. In the gain domain, participants typically prefer the lottery for low sure payments, but switch as the sure payment rises. This behavior is reversed in the loss domain. The point where participants switch from the lottery to the sure payment is called the certainty equivalent. At the certainty equivalent a participant is just indifferent between the lottery and the sure payment. In the loss domain, outcomes were realized by subtraction from an initial endowment. There were a total of 28 decision tasks including 14 for gains, 13 for losses and 1 for mixed outcomes (i.e., gains and losses). In total, participants 881 decisions in these 28 lottery tasks. For mixed lotteries, we aimed at fixing the certainty equivalent to zero. Therefore, we asked participants here to state a loss that makes them indifferent between playing a 50/50 lottery involving a certain price and the stated loss, or receiving zero for sure.

In Vietnam, the orders of the experiment were counter-balanced. We found no order effects in our data, and using a fixed order was found to reduce the cognitive burden for our subjects. We thus decided to present the task in a fixed order in Germany, where participants were presented gains first, then losses and mixed prospects in order.

The experiments were run with pen and paper in both countries. As a standard procedure, one choice was randomly selected to be paid. The possible payments for this task ranged from $€ 4$ to $€ 44$ in purchasing power parity, including a fixed participation 
payment of $€ 4$. On average, participants spent 30 minutes to complete the lottery tasks. The whole procedure including hand scanning and the follow-up questionnaire, took about 1 hour.

\section{D:4D}

In Germany, both hands were scanned with a high-resolution scanner (Epson V370 Photo). In Vietnam, the hands were photocopied, and the 2D:4D ratios were measured from a subsequent scan of these photocopies. To determine 2D:4D, we measured the lengths of the index and ring digits on both hands from basal crease to the finger tip using GIMP image editting software. As the right hand 2D:4D shows greater sex differences (see Hönekopp and Watson, 2010) a large body of the literature on 2D:4D use only right hand ratios in their analysis. The current study focuses on the right hand 2D:4D as well. However, the complete analysis of both hands can be found in the appendix.

Table 2: Mean of 2D:4Ds by sex and country

\begin{tabular}{lccclllll}
\hline & \multicolumn{3}{c}{ left hand 2D:4D } & & \multicolumn{3}{c}{ right hand 2D:4D } \\
\cline { 2 - 3 } & Germany & Vietnam & difference & & Germany & Vietnam & difference \\
\hline male & 0.960 & 0.937 & $p<0.001$ & & 0.955 & 0.950 & $p=0.209$ \\
& $(0.028)$ & $(0.035)$ & $d=0.710$ & & $(0.027)$ & $(0.031)$ & $d=0.194$ \\
female & 0.962 & 0.963 & $p=0.822$ & & 0.965 & 0.974 & $p=0.083$ \\
& $(0.033)$ & $(0.036)$ & $d=0.033$ & & $(0.039)$ & $(0.039)$ & $d=0.258$ \\
\hline difference & $p=0.623$ & $p<0.001$ & & & $p=0.046$ & $p<0.001$ & \\
effect size & $d=0.071$ & $d=0.722$ & & & $d=0.291$ & $d=0.688$ & \\
\hline
\end{tabular}

Table 2 shows the average 2D:4D by sex and country, separately for the left and the right hands. Standard deviations are given in parantheses. The means are tested against each other using t-tests. Effect sizes (Cohen's d) are also reported in the table. Men have significant lower right hand 2D:4D than women both in Germany and Vietnam ( $p=0.046, d=0.291$ and $p<0.01, d=0.688$ respectively). Men have significantly lower left 2D:4D than women in Vietnamese sample too $(p<0.001)$. In the German sample though, left hand ratios are quite similar with men having a 0.002 lower ratio than women on average. These differences are in line with the literature and the meta study of Hönekopp and Watson (2010). Both left and right hand ratios of Vietnamese men are lower than German men. The difference is statistically significant for the left hand $(p<0.001, d=0.710)$ but not for the right $(p=0.059, d=0.325)$. Women in Vietnamese sample have slightly higher ratios than the ones in the German sample, 
although differences are not strong $(p=0.822, d=0.033$ for the left and $p=0.083$, $d=0.258$ for the right).

\section{Results}

\section{Descriptive analysis of risk preferences}

We start with a descriptive analysis of risk preferences elicited across the different decision domains. Figure 1 and 2 show normalized certainty equivalents $\pi_{i}$ by probability of winning or losing. We only show our indices for changing probabilities of obtaining a fixed outcome of $€ 20$ or else nothing. While equivalent indices for different outcome sizes are easily constructed, the latter add nothing to our analysis, and all conclusions drawn in this section remain stable to including such measures.

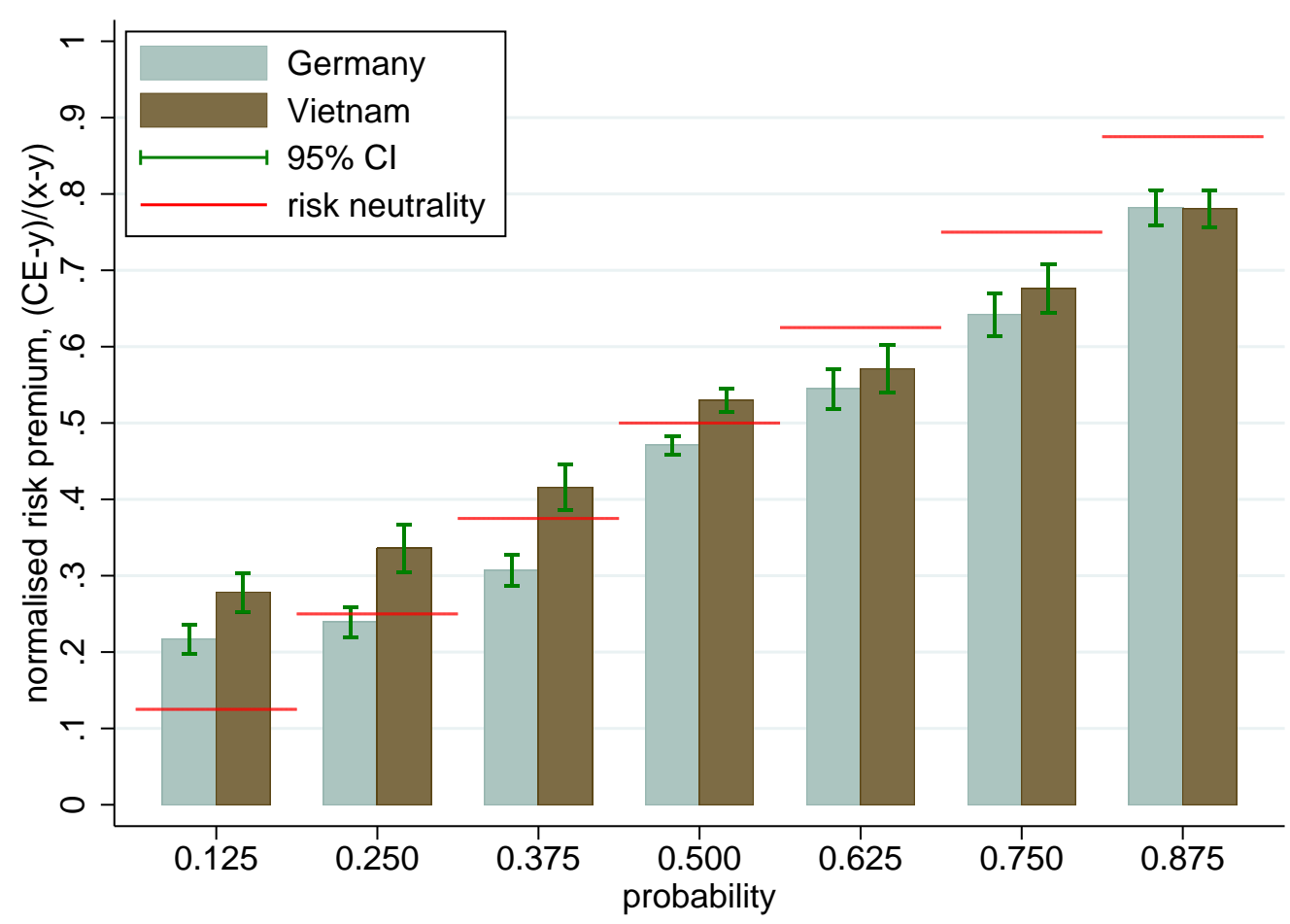

Figure 1: Risk preferences in the gain domain by probability and country.

We start from the results for gains, shown in Figure 1. For the smallest probability of $p=0.125, \pi_{i}$ is significantly higher than the objective probability of winning the prize, indicating risk seeking behavior. This changes as probabilities increase. Already at $p=0.375$, subjects in Germany are significantly risk averse on average, and risk 
aversion increases further with probabilities. For subjects in Vietnam, we observe a similar tendency, except that they become risk averse only at the much larger probability of $p=0.625$. The pattern of risk aversion increasing in probability is consistent with probabilistic insensitivity (see Section 2). The Vietnamese students are more risk taking on average than the German students $(z=-4.020, p<0.001, N=364$, Mann-Whitney test on average normalized certainty equivalents for gains). This result corresponds closely to previous comparative studies, which found risk aversion to increase in GDP per capita for gains (Rieger et al., 2014; L'Haridon and Vieider, 2018).

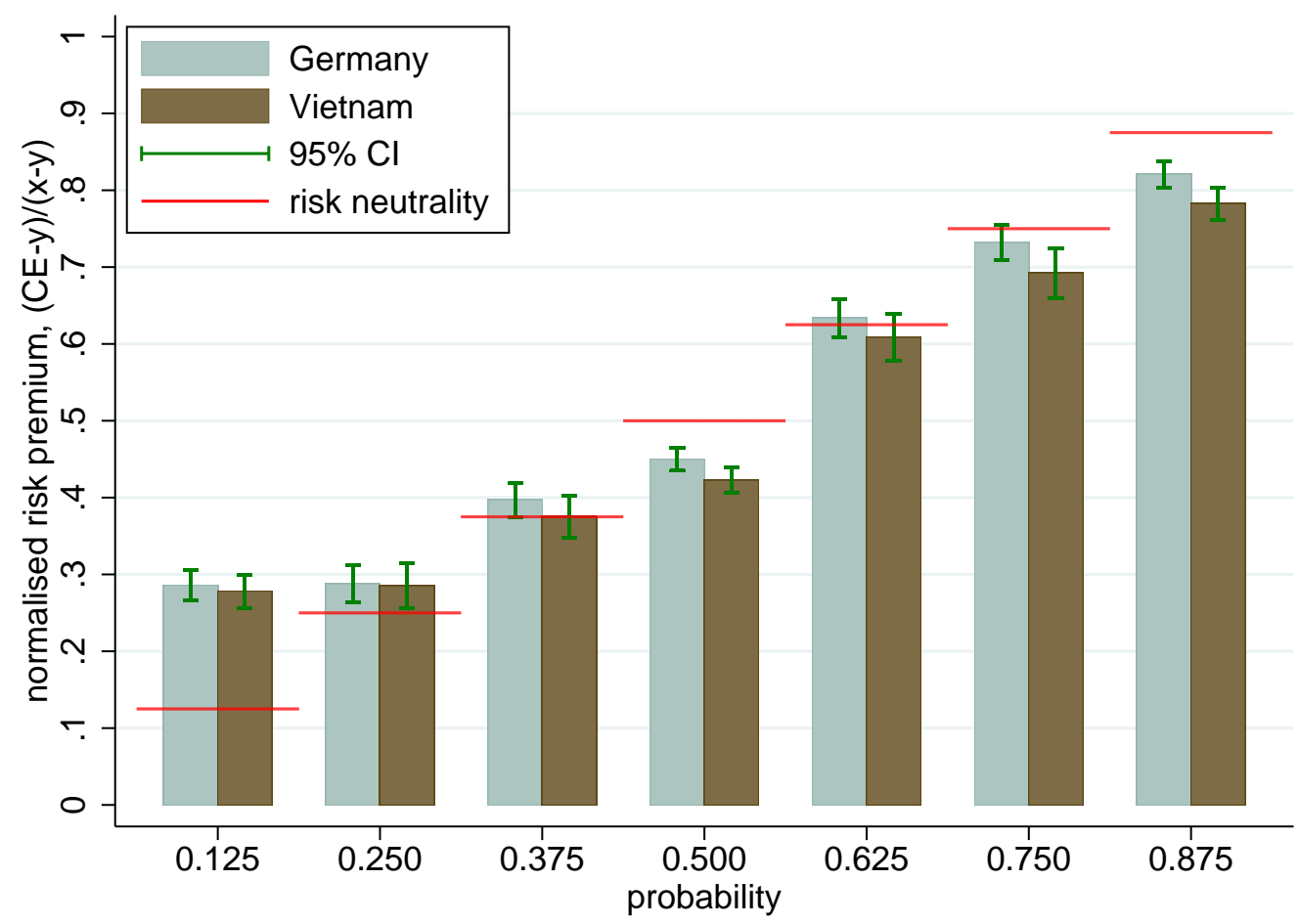

Figure 2: Risk preferences in the loss domain by probability and country.

An equivalent graph for losses is shown in Figure 2. We can now think of these values as insurance premia, since they are the absolute amounts that the subjects are willing to forgo to avoid playing a given prospect. The interpretation is thus reversed relative to gains, with values higher than the probability indicating risk aversion, and lower values indicating risk seeking. For the lowest probability, we now find risk aversion in both countries. As the probability increases, this risk aversion decreases and gives way to risk seeking for the highest probability level. As implied by prospect theory, this trend thus mirrors the one found for gains. While Germany and Vietnam exhibit 
very similar patterns of risk preferences for low probabilities, our Vietnamese subjects are more risk seeking than our German subjects for large probabilities. On average, our Vietnamese subjects are thus again more risk seeking than our German subjects $\left(z=2.490, p=0.012, N=363\right.$, Mann-Whitney test on average $\pi_{i}$ for losses). This again corresponds to patterns found using the same tasks by Vieider et al. (2012) and L'Haridon and Vieider (2018), but it contradicts a correlation with GDP per capita in the opposite direction found by Rieger et al. (2014) using hypothetical willingness to accept for lotteries. ${ }^{5}$

Finally, we analyze the mixed prospect, where we find no significant difference between Germany and Vietnam in terms of risk aversion $(z=-1.081, p=0.280, N=364)$. On average, we find the acceptable loss is slightly smaller than half the gain. This matches the popular adage that losses loom about twice as large as gains, and our results in terms of the GLR are remarkably consistent with the median loss aversion estimate of 2.25 reported by Tversky and Kahneman (1992). It also means that we find considerably more risk aversion over mixed prospects than for either gains or losses, where we found risk preferences close to risk neutrality for the same probability (although with some differences across countries and decision domains, as discussed above). This is again quite typical, as loss aversion is thought to account for most of risk aversion over small stakes (Köbberling and Wakker, 2005; Rabin, 2000).

\section{D:4D and risk preferences}

We can now regress our measures of risk preferences on the independent variables of interest. We present the regression analyses by decision domains and countries. Table 3 shows the results for gains and losses. All regressions are random effects OLS regressions, with standard errors clustered at the subject level. This allows us to enter the probability level as an independent variable capturing within-subject variance in risk preferences. The differing number of subjects across regressions is due to some unreadable hand scans, as outlined above. RDR $\mathrm{x}$ female and RDR $\mathrm{x}$ probability are the interaction variables. The first four columns present the regressions for Germany and the latter four for Vietnam. Models I, II and V, VI are the regressions of the loss domain and the models III, IV and VII, VIII are of the gain domain. Note that our analyses include participants who

\footnotetext{
${ }^{5}$ Rieger et al. (2014) used WTP for gains, but WTA for losses. This changes the references point, and may explain the opposing effects found across outcome domains.
} 
completed corresponding lotteries entirely and consistently. The missing observations are due to multiple switches in the lotteries or lotteries without responses. ${ }^{6}$

Table 3: Regression analysis for gains and losses in both countries

\begin{tabular}{|c|c|c|c|c|c|c|c|c|}
\hline \multirow{3}{*}{$\begin{array}{l}\text { Dep. var: } \\
\pi_{i}\end{array}$} & \multicolumn{4}{|c|}{ Germany } & \multicolumn{4}{|c|}{ Vietnam } \\
\hline & \multicolumn{2}{|c|}{ Losses } & \multicolumn{2}{|c|}{ Gains } & \multicolumn{2}{|c|}{ Losses } & \multicolumn{2}{|c|}{ Gains } \\
\hline & I & II & III & IV & $\mathrm{V}$ & VI & VII & VIII \\
\hline probability & $\begin{array}{c}0.764^{* * *} \\
(0.020)\end{array}$ & $\begin{array}{c}0.764 * * * \\
(0.020)\end{array}$ & $\begin{array}{c}0.779 * * * \\
(0.023)\end{array}$ & $\begin{array}{c}0.779 * * * \\
(0.023)\end{array}$ & $\begin{array}{c}0.708^{* * * *} \\
(0.025)\end{array}$ & $\begin{array}{c}0.707^{* * *} \\
(0.025)\end{array}$ & $\begin{array}{c}0.668^{* * * *} \\
(0.028)\end{array}$ & $\begin{array}{c}0.668^{* * *} \\
(0.028)\end{array}$ \\
\hline RDR & $\begin{array}{c}0.003 \\
(0.012)\end{array}$ & $\begin{array}{c}0.005 \\
(0.015)\end{array}$ & $\begin{array}{c}0.001 \\
(0.018)\end{array}$ & $\begin{array}{c}0.017 \\
(0.018)\end{array}$ & $\begin{array}{l}-0.010 \\
(0.014)\end{array}$ & $\begin{array}{l}-0.022 \\
(0.019)\end{array}$ & $\begin{array}{c}0.006 \\
(0.019)\end{array}$ & $\begin{array}{c}0.011 \\
(0.026)\end{array}$ \\
\hline RDR $x$ female & $\begin{array}{l}-0.011 \\
(0.014)\end{array}$ & $\begin{array}{l}-0.011 \\
(0.014)\end{array}$ & $\begin{array}{l}-0.007 \\
(0.020)\end{array}$ & $\begin{array}{l}-0.007 \\
(0.020)\end{array}$ & $\begin{array}{l}0.020 \\
(0.017)\end{array}$ & $\begin{array}{l}0.020 \\
(0.017)\end{array}$ & $\begin{array}{l}-0.004 \\
(0.023)\end{array}$ & $\begin{array}{l}-0.004 \\
(0.023)\end{array}$ \\
\hline RDR $x$ probability & $\begin{array}{l}- \\
- \\
-\end{array}$ & $\begin{array}{c}-0.004 \\
(0.026)\end{array}$ & $\begin{array}{l}- \\
- \\
-\end{array}$ & $\begin{array}{l}-0.031 \\
(0.023)\end{array}$ & $\begin{array}{l}- \\
- \\
-\end{array}$ & $\begin{array}{c}0.025 \\
(0.026)\end{array}$ & $\begin{array}{l}- \\
- \\
-\end{array}$ & $\begin{array}{l}-0.011 \\
(0.027)\end{array}$ \\
\hline female & $\begin{array}{l}-0.007 \\
(0.013)\end{array}$ & $\begin{array}{l}-0.007 \\
(0.013)\end{array}$ & $\begin{array}{l}-0.007 \\
(0.020)\end{array}$ & $\begin{array}{l}-0.009 \\
(0.018)\end{array}$ & $\begin{array}{c}0.007 \\
(0.018)\end{array}$ & $\begin{array}{c}0.007 \\
(0.018)\end{array}$ & $\begin{array}{c}-0.095^{* * *} \\
(0.024)\end{array}$ & $\begin{array}{c}-0.095 * * * \\
(0.024)\end{array}$ \\
\hline constant & $\begin{array}{c}0.122^{* * *} \\
(0.014)\end{array}$ & $\begin{array}{c}0.122^{* * *} \\
(0.014)\end{array}$ & $\begin{array}{c}0.080^{* * * *} \\
(0.015)\end{array}$ & $\begin{array}{c}0.081^{* * *} \\
(0.015)\end{array}$ & $\begin{array}{c}0.117^{* * * *} \\
(0.017)\end{array}$ & $\begin{array}{c}0.112^{* * *} \\
(0.017)\end{array}$ & $\begin{array}{c}0.240^{* * * *} \\
(0.024)\end{array}$ & $\begin{array}{c}0.240^{* * *} \\
(0.024)\end{array}$ \\
\hline Observations & 2431 & 2431 & 2562 & 2562 & 2093 & 2093 & 2268 & 2268 \\
\hline Subjects (clusters) & 187 & 187 & 183 & 183 & 161 & 161 & 162 & 162 \\
\hline$R^{2}$ within & 0.48 & 0.48 & 0.54 & 0.54 & 0.42 & 0.42 & 0.45 & 0.45 \\
\hline$R^{2}$ between & 0.01 & 0.01 & 0.01 & 0.01 & 0.01 & 0.01 & 0.09 & 0.09 \\
\hline
\end{tabular}

certainty equivalent; RDR is the right 2D:4D; 2D:4Ds are entered as z-scores; female is a dummy variable with 1 for women.

The coefficient of the probability variable is always significantly lower than 1 , indicating the probabilistic insensitivity - a coefficient lower than 1 indicates that the $\pi_{i}$ indicex varies less than proportionately with the probability of winning the constant prize. The coefficient is generally lower for Vietnam, indicating lower probabilistic sensitivity in Vietnam.

We do not observe any significant effect of 2D:4D in either country or either domains. We also find no significant effect of the 2D:4D either for males (indicated by the 2D:4D variable, which indicates a main effect for males only) or for females (as captured by the interaction effect). The interaction between the $2 \mathrm{D}: 4 \mathrm{D}$ and the probability coefficient is insignificant and shows that probabilistic insensitivity is not related to $2 \mathrm{D}: 4 \mathrm{Ds}$. We do not observe any gender effects in risk taking in Germany. For Vietnam, we find a strong gender effect, going in the expected direction of women being more risk averse than men.

Table 4 shows the regressions of our measure of risk aversion in the mixed gainloss domain on the usual independent variables. A larger GLR indicates increased risk aversion. Since we do not have repeated observations, we now use OLS regressions. The first regression examines the effects for the right hand 2D:4Ds on the GLR in Germany

\footnotetext{
${ }^{6}$ The pooled regressions that include both coutries can be found in the appendix
} 
Table 4: Regression analysis for mixed prospects in both countries

\begin{tabular}{lcc}
\hline Dep. var: GLR & Germany & Vietnam \\
\hline RDR & 0.398 & -0.029 \\
& $(0.315)$ & $(0.107)$ \\
RDR x female & -0.315 & 0.065 \\
& $(0.339)$ & $(0.228)$ \\
female & -0.013 & $0.800^{* * *}$ \\
& $(0.222)$ & $(0.249)$ \\
constant & $2.210^{* * *}$ & $1.948^{* * *}$ \\
& $(0.181)$ & $(0.129)$ \\
\hline Subjects & 188 & 162 \\
$R^{2}$ & 0.03 & 0.06 \\
\hline Standard errors in parentheses; * ** *** indicate significance \\
at the 10, 5 and 1 \% level respectively; GLR is the Gain-Loss \\
Ratio; RDR is the right hand 2D:4D; 2D:4Ds are entered as \\
z-scores; female is a dummy variable with 1 for women.
\end{tabular}

and the second in Vietnam. Again, we find no effects in terms of 2D:4Ds. We do, however, find a gender effect in the expected direction of women being more risk averse than men.

\section{Discussion}

This study provided a systematic analysis of 2D:4D and risk preferences using an incentivized, extensive risk elicitation method. Although several studies in the literature suggested a positive correlation between 2D:4D and risk aversion, the results were not conclusivee and they were obtained from various samples and with coarse risk elicitation methods. Our results do not show any significant relationship between 2D:4D and risk taking neither in pure gains and loss nor in the mixed domains. This null result is consistent both in our Caucasian and Asian samples.

As a starting point, we suspected that the mixed evidence in the literature could be due to over-simplified risk elicitation methods that are based on expected utility theory. It has been repeatedly documented that expected utility theory is typically violated by decision makers (Starmer, 2000b). In particular, different elicitation mechanisms may be affected by loss aversion to differing degrees, thus accounting for the inconsistent conclusions reached in the literature. Prospect theory explicitly separates and identifies different aspects of risk preferences by introducing probabilistic insensitivity and distinguishing pure gain, pure loss and mixed prospects. With the task of Vieider et al. (2015) 
we were able to study the above-mentioned aspects of risk preferences in detail. In particular, the design of the tasks was suchn as to explicitly avoid endogenous reference points in the elicitation of risk attitudes over gains and losses (Hershey and Schoemaker, 1985; Vieider, 2018), which allowed us to cleanly separate risk preference in the pure outcome domains from preferences over mixed gain-loss prospects.

Furthermore, according to dual inheritence theory (or gene-culture co-evolution) human behavior is shaped both by cultural and genetic factors (Boyd and Richerson, 1988; Richerson et al., 2010). As twin studies suggest that 2D:4D might be heritable, the relationship between behavior and 2D:4D may support dual inheritence theory (Paul et al., 2006). Furthermore, there is also a body of literature suggesting that genetic inheritance has a partial role in economic behavior (Zhong et al., 2009; Cesarini et al., 2009) and prospect theory has become an important benchmark for evolutionary theories like, risk-sensitive-foraging theoris (Kacelnik and El Mouden, 2013; Houston et al., 1993). These evidences make prospect theory an ideal device to analyze the relationship between 2D:4D and risk taking. Yet, our study did not detect any significant relationship between 2D:4D and risk taking in the framework of prospect theory.

One needs to apply considerable caution before interpreting results from this literature in a causal manner. The significant results in the literature do not suggest a direct biological channel that affects decision making process. The first reason is that we cannot disentangle if the genetic factor effects the decision making directly or if it mediates the cultural and environmental development of the decision patterns of individuals. In other words, PTE may have a partial role on the personality development and cognition rather than decision making itself. On the other hand, there is evidence that short term peaks of circulating testosterone can be organized by PTE suggesting a negative relationship between 2D:4D and sensitivity to testosterone (Crewther et al., 2015). Typically, these peaks are observed more in men than women (Manning et al., 2014). If this is the case the impact of 2D:4D on decision making would be via circulating testosterone.

Also, determinants of prenatal androgen exposure levels are not yet sufficiently understood, and some studies have presented evidence suggesting that there may be interactions between socio-economic status of the parents and biological determinants of prenatal androgen exposure. For example Toriola et al. (2011) showed that smoking and maternal age have significant impacts on sex steroid levels during the first half of the pregnancy. As smoking has been associated with low income and lower education (see 
Hiscock et al. (2012) for a review), biology and and socio-economic status of the parents may jointly affect prenatal androgen exposure levels. Complex processes may thus be at work, and much richer data on both biological and socio-economic variables for both children and parents will be needed to cleanly disentangle the different channels.

Finally, the literature studying the associations between 2D:4D and economic behavior usually work with small samples and they usually do not register their pre-analysis plans beforehands. To the best of our knowledge, Parslow et al. (2018) is the only study which has a prior pre-analysis plan registered. As a result of possible publication biases, researcher degrees of freedom and false positive results, it gets even more challenging to reach a consensus on whether 2D:4D actually correlates with certain economic decisions.

\section{Acknowledgements}

This study was funded by Leibniz Institute (Project SAW-2013-IfW-2 219). 


\section{References}

Abdellaoui, M., Diecidue, E., and Öncüler, A. (2011). Risk preferences at different time periods: An experimental investigation. Management Science, 57(5):975-987.

Allais, M. (1953). Le comportement de l'homme rationnel devant le risque: critique des postulats et axiomes de l'école américaine. Econometrica, 21(4):503-546.

Alonso, J., Di Paolo, R., Ponti, G., and Sartarelli, M. (2018). Facts and misconceptions about 2d:4d, social and risk preferences. Frontiers in Behavioral Neuroscience, 12:22.

Apicella, C. L., Dreber, A., Campbell, B., Gray, P. B., Hoffman, M., and Little, A. C. (2008). Testosterone and financial risk preferences. Evolution and Human Behavior, 29(6):384-390.

Aycinena, D., Baltaduonis, R., and Rentschler, L. (2014). Risk preferences and prenatal exposure to sex hormones for ladinos. PLOS ONE, 9(8):e103332.

Barel, E. (2017). 2d: 4d, optimism, and risk taking. Current Psychology, pages 1-9.

Bock, O., Baetge, I., and Nicklisch, A. (2014). hroot: Hamburg registration and organization online tool. European Economic Review, 71(10):117-120.

Bönte, W., Procher, V. D., and Urbig, D. (2016). Biology and selection into entrepreneurship: The relevance of prenatal testosterone exposure. Entrepreneurship Theory and Practice, 40(5):1121-1148.

Boyd, R. and Richerson, P. J. (1988). Culture and the evolutionary process. University of Chicago press.

Brañas-Garza, P., Galizzi, M. M. G., and Nieboer, J. (2018). Experimental and selfreported measures of risk taking and digit ratio (2D:4D): Evidence from a large, systematic study Pablo Brañas-Garza. International Economic Review, (0).

Brañas-Garza, P., Kovářík, J., and Neyse, L. (2013). Second-to-fourth digit ratio has a non-monotonic impact on altruism. PloS one, 8(4):e60419.

Brañas-Garza, P. and Rustichini, A. (2011). Organizing effects of testosterone and economic behavior: Not just risk taking. PLOS ONE, 6(12):e29842.

Brown, W. M., Hines, M., Fane, B. A., and Breedlove, S. M. (2002). Masculinized finger length patterns in human males and females with congenital adrenal hyperplasia. Hormones and behavior, 42(4):380-386.

Buser, T. (2012). Digit ratios, the menstrual cycle and social preferences. Games and Economic Behavior, 76(2):457-470. 
Cesarini, D., Dawes, C. T., Johannesson, M., Lichtenstein, P., and Wallace, B. (2009). Genetic variation in preferences for giving and risk taking. The Quarterly Journal of Economics, 124(2):809-842.

Chen, M. K., Lakshminarayanan, V., and Santos, L. R. (2006). How basic are behavioral biases? evidence from capuchin monkey trading behavior. Journal of Political Economy, 114(3):517-537.

Chicaiza-Becerra, L. A. and Garcia-Molina, M. (2017). Prenatal testosterone predicts financial risk taking: evidence from latin america. Personality and Individual Differences, 116:32-37.

Coates, J. M., Gurnell, M., and Rustichini, A. (2009). Second-to-fourth digit ratio predicts success among high-frequency financial traders. Proceedings of the National Academy of Sciences of the United States of America, 106(2):623-628.

Cohen, M., Jaffray, J.-Y., and Said, T. (1987). Experimental comparison of individual behavior under risk and under uncertainty for gains and for losses. Organizational Behavior and Human Decision Processes, 39(1):1-22.

Crewther, B., Cook, C., Kilduff, L., and Manning, J. (2015). Digit ratio (2D:4D) and salivary testosterone, oestradiol and cortisol levels under challenge: Evidence for prenatal effects on adult endocrine responses. Early Human Development, 91(8):451-456.

Dalton, P. S. and Ghosal, S. (2018). Self-confidence, overconfidence and prenatal testosterone exposure: Evidence from the lab. Frontiers in behavioral neuroscience, 12:5.

De Martino, B., Camerer, C. F., and Adolphs, R. (2010). Amygdala damage eliminates monetary loss aversion. Proceedings of the National Academy of Sciences of the United States of America, 107(8):3788-3792.

Dhami, S. (2016). The Foundations of Behavioral Economic Analysis. Oxford University Press.

Dreber, A. and Hoffman, M. (2007). Portfolio selection in utero. Working Paper. url: sites.google.com/site/hoffmanmoshe/PortfolioSelectioninUtero.doc, accessed May 2016.

Drichoutis, A. C. and Nayga, R. M. (2015). Do risk and time preferences have biological roots? Southern Economic Journal, 82(1):235-256.

Eckel, C. C. and Grossman, P. J. (2008). Men, women and risk aversion: Experimental evidence. In Plott, C. and Vernon, S., editors, Handbook of experimental economics 
results, chapter 113, pages 1061-1073. Elsevier, New York.

Filippin, A. and Crosetto, P. (2016). A reconsideration of gender differences in risk attitudes. Management Science. Articles in advance.

Friedl, A., Neyse, L., and Schmidt, U. (2018). Payment scheme changes and effort adjustment: the role of 2d: $4 \mathrm{~d}$ digit ratio. Journal of Behavioral and Experimental Economics, 72:86-94.

Gächter, S., Johnson, E. J., and Herrmann, A. (2007). Individual-level loss aversion in riskless and risky choices.

Galizzi, M. M. and Nieboer, J. (2015). Digit ratio (2D:4D) and altruism: Evidence from a large, multi-ethnic sample. Frontiers in Behavioral Neuroscience, 9:41.

Ganzach, Y. and Karsahi, N. (1995). Message framing and buying behavior: A field experiment. Journal of Business Research, 32(1):11-17.

Garbarino, E., Slonim, R., and Sydnor, J. (2011). Digit ratios (2D:4D) as predictors of risky decision making for both sexes. Journal of Risk and Uncertainty, 42(1):1-26.

Gneezy, U. and Potters, J. (1997). An experiment on risk taking and evaluation periods. Quarterly Journal of Economics, 112(2):631-645.

Goy, R. and McEwen, B. (1980). Sexual differentiation of the brain. MIT Press, Cambridge.

Guiso, L. and Rustichini, A. (2018). What drives women out of management? the joint role of testosterone and culture. European Economic Review, 109:221-237.

Harbaugh, W. T., Krause, K., and Vesterlund, L. (2010). The fourfold pattern of risk attitudes in choice and pricing tasks. Economic Journal, 120(545):595-611.

Hermann, D. (2017). Determinants of financial loss aversion: The influence of prenatal androgen exposure (2d: 4d). Personality and Individual Differences, 117:273-279.

Hershey, J. C. and Schoemaker, P. J. H. (1985). Probability versus Certainty Equivalence Methods in Utility Measurement: Are They Equivalent? Management Science, 31(10):1213-1231.

Hiscock, R., Bauld, L., Amos, A., Fidler, J. A., and Munafò, M. (2012). Socioeconomic status and smoking: a review. Annals of the New York Academy of Sciences, 1248(1):107-123.

Hochman, G. and Yechiam, E. (2011). Loss aversion in the eye and in the heart: The autonomic nervous system's responses to losses. Journal of Behavioral Decision Making, 
$24(2): 140-156$.

Holt, C. A. and Laury, S. K. (2002). Risk aversion and incentive effects. American Economic Review, 92(5):1644-1655.

Hönekopp, J. and Watson, S. (2010). Meta-analysis of digit ratio 2D:4D shows greater sex difference in the right hand. American Journal of Human Biology, 22(5):619-630.

Houston, A. I., McNamara, J. M., and Hutchinson, J. M. (1993). General results concerning the trade-off between gaining energy and avoiding predation. Phil. Trans. R. Soc. Lond. B, 341(1298):375-397.

Kacelnik, A. and El Mouden, C. (2013). Triumphs and trials of the risk paradigm. Animal Behaviour, 86(6):1117-1129.

Kahneman, D., Knetsch, J. L., and Thaler, R. H. (1990). Experimental tests of the endowment effect and the coase theorem. Journal of Political Economy, 98(6):13251348.

Kahneman, D. and Tversky, A. (1979). Prospect theory: An analysis of decision under risk. Econometrica, 47(2):263-291.

Köbberling, V. and Wakker, P. P. (2005). An index of loss aversion. Journal of Economic Theory, 122(1):119-131.

Lakshminarayanan, V. R., Chen, M. K., and Santos, L. R. (2011). The evolution of decision-making under risk: framing effects in monkey risk preferences. Journal of Experimental Social Psychology, 47(3):689-693.

L'Haridon, O. and Vieider, F. M. (2018). All over the map: a worldwide comparison of risk preferences. Quantitative Economics, Forthcoming.

Lima de Miranda, K., Neyse, L., and Schmidt, U. (2018). Risk preferences and predictions about others: No association with 2d:4d ratio. Frontiers in Behavioral Neuroscience, $12: 9$.

Lutchmaya, S., Baron-Cohen, S., Raggatt, P., Knickmeyer, R., and Manning, J. T. (2004). 2nd to 4th digit ratios, fetal testosterone and estradiol. Early Human Development, 77(1-2):23-28.

Manning, J., Kilduff, L., Cook, C., Crewther, B., and Fink, B. (2014). Digit ratio (2D:4D): A biomarker for prenatal sex steroids and adult sex steroids in challenge situations. Frontiers in Endocrinology, 5:9.

Manning, J. T. (2002). Digit ratio: A pointer to fertility, behavior, and health. Rutgers 
University Press, New Jersey.

Manning, J. T., Kilduff, L. P., and Trivers, R. (2013). Digit ratio (2d: 4d) in klinefelter's syndrome. Andrology, 1(1):94-99.

McDermott, R., Fowler, J. H., and Smirnov, O. (2008). On the evolutionary origin of prospect theory preferences. The Journal of Politics, 70(2):335-350.

McGraw, A. P., Larsen, J. T., Kahneman, D., and Schkade, D. (2010). Comparing gains and losses. Psychological Science, 21(10):1438-1445.

McIntyre, M. H. (2006). The use of digit ratios as markers for perinatal androgen action. Reproductive biology and endocrinology, 4(1):10.

Neyse, L., Bosworth, S., Ring, P., and Schmidt, U. (2016). Overconfidence, incentives and digit ratio. Scientific Reports, 6:23294.

Parslow, E., Ranehill, E., Zethraeus, N., Blomberg, L., von Schoultz, B., Lindén Hirschberg, A., Johannesson, M., and Dreber, A. (2018). The digit ratio (2d: 4d) and economic preferences: No robust associations in a sample of 330 women. Available at SSRN 3238048 doi: 10.2139/ssrn.3238048.

Paul, S. N., Kato, B. S., Cherkas, L. F., Andrew, T., and Spector, T. D. (2006). Heritability of the second to fourth digit ratio (2d:4d): A twin study. Twin Research and Human Genetics, 9(2):215-219.

Pearson, M. and Schipper, B. C. (2012). The visible hand: Finger ratio (2D:4D) and competitive bidding. Experimental Economics, 15(3):510-529.

Pratt, J. W. (1964). Risk aversion in the small and in the large. Econometrica, 32:122136.

Rabin, M. (2000). Risk aversion and expected-utility theory: A calibration theorem. Econometrica, 68(5):1281-1292.

Richerson, P. J., Boyd, R., and Henrich, J. (2010). Gene-culture coevolution in the age of genomics. Proceedings of the National Academy of Sciences, 107(Supplement 2):8985-8992.

Rieger, M. O., Wang, M., and Hens, T. (2014). Risk preferences around the world. Management Science, 61(3):637-648.

Ronay, R. and Von Hippel, W. (2010). Power, testosterone, and risk-taking. Journal of Behavioral Decision Making, 23(5):473-482.

Sapienza, P., Zingales, L., and Maestripieri, D. (2009). Gender differences in financial risk 
aversion and career choices are affected by testosterone. Proceedings of the National Academy of Sciences of the United States of America, 106(36):15268-15273.

Schipper, B. C. (2012). Sex hormones and choice under risk. Working Paper. url: http:// faculty.econ.ucdavis.edu/faculty/schipper/hormrisk.pdf, accessed May 2016.

Sokol-Hessner, P., Hsu, M., Curley, N. G., Delgado, M. R., Camerer, C. F., and Phelps, E. A. (2009). Thinking like a trader selectively reduces individuals' loss aversion. Proceedings of the National Academy of Sciences of the United States of America, 106(13):5035-40.

Starmer, C. (2000a). Developments in Non-Expected Utility Theory: The Hunt for a Descriptive Theory of Choice under Risk. Journal of Economic Literature, 38:332-382.

Starmer, C. (2000b). Developments in non-expected utility theory: The hunt for a descriptive theory of choice under risk. Journal of economic literature, 38(2):332-382.

Stenstrom, E., Saad, G., Nepomuceno, M. V., and Mendenhall, Z. (2011). Testosterone and domain-specific risk: Digit ratios (2d: 4d and rel2) as predictors of recreational, financial, and social risk-taking behaviors. Personality and Individual Differences, 51(4):412-416.

Tom, S. M., Fox, C. R., Poldrack, R. A., and Trepel, C. (2007). The neural basis of loss aversion in decision-making under risk. Science, 315(5811):515-518.

Toriola, A. T., Vääräsmäki, M., Lehtinen, M., Zeleniuch-Jacquotte, A., Lundin, E., Rodgers, K.-G., Lakso, H.-A., Chen, T., Schock, H., Hallmans, G., et al. (2011). Determinants of maternal sex steroids during the first half of pregnancy. Obstetrics and gynecology, 118(5):1029.

Tversky, A. and Fox, C. R. (1995). Weighing risk and uncertainty. Psychological Review, 102(2):269.

Tversky, A. and Kahneman, D. (1992). Advances in prospect theory: Cumulative representation of uncertainty. Journal of Risk and Uncertainty, 5(4):297-323.

van Anders, S. M., Vernon, P. A., and Wilbur, C. J. (2006). Finger-length ratios show evidence of prenatal hormone-transfer between opposite-sex twins. Hormones and Behavior, 49(3):315-319.

Ventura, T., Gomes, M., Pita, A., Neto, M., and Taylor, A. (2013). Digit ratio (2d: 4d) in newborns: influences of prenatal testosterone and maternal environment. Early Human Development, 89(2):107-112. 
Vieider, F. M. (2018). Certainty Preference, Random Choice, and Loss Aversion: A Comment on "Violence and Risk Preference: Experimental Evidence from Afghanistan". American Economic Review, forthcoming.

Vieider, F. M., Chmura, T., and Martinsson, P. (2012). Risk attitudes, development, and growth: Macroeconomic evidence from experiments in 30 countries. Working Paper. url: http://www.ferdinandvieider.com/risk_development_growth.pdf, accessed May 2016.

Vieider, F. M., Lefebvre, M., Bouchouicha, R., Chmura, T., Hakimov, R., Krawczyk, M., and Martinsson, P. (2015). Common components of risk and uncertainty attitudes across contexts and domains: Evidence from 30 countries. Journal of the European Economic Association, 13(3):421-452.

von Neumann, J. and Morgenstern, O. (1944). Theory of games and economic behavior. Princeton University Press, New Jersey.

Wakker, P. P. (2010a). Prospect theory: For risk and ambiguity. Cambridge University Press, Cambridge.

Wakker, P. P. (2010b). Prospect Theory for Risk and Ambiguity. Cambridge University Press, Cambridge.

Wehrung, D. A., Lee, K.-H., David, K. T., and Vertinsky, I. B. (1989). Adjusting risky situations: A theoretical framework and empirical test. Journal of Risk and Uncertainty, 2(2):189-212.

Wu, G. and Gonzalez, R. (1996). Curvature of the probability weighting function. Management Science, 42(12):1676-1690.

Zheng, Z. and Cohn, M. J. (2011). Developmental basis of sexually dimorphic digit ratios. Proceedings of the National Academy of Sciences of the United States of America, 108(39):16289-94.

Zhong, S., Chew, S. H., Set, E., Zhang, J., Xue, H., Sham, P. C., Ebstein, R. P., and Israel, S. (2009). The heritability of attitude toward economic risk. Twin Research and Human Genetics, 12(1):103-107. 


\section{Risk Attitudes and Digit Ratio (2D:4D): Evidence from Prospect Theory}

\section{Appendix}

Levent Neyse, Ferdinand M. Vieider, Patrick Ring, Catharina Probst, Christian Kaernbach, Thilo van Eimeren and Ulrich Schmidt

Table 1: Regression analysis for gains and losses in both countries

\begin{tabular}{|c|c|c|c|c|c|c|c|c|}
\hline \multirow{3}{*}{$\begin{array}{l}\text { Dep. var: } \\
\pi_{i}\end{array}$} & \multicolumn{4}{|c|}{ Germany } & \multicolumn{4}{|c|}{ Vietnam } \\
\hline & \multicolumn{2}{|c|}{ Losses } & \multicolumn{2}{|c|}{ Gains } & \multicolumn{2}{|c|}{ Losses } & \multicolumn{2}{|c|}{ Gains } \\
\hline & I & II & III & IV & $\mathrm{V}$ & VI & VII & VIII \\
\hline probability & $\begin{array}{c}0.765^{* * * *} \\
(0.021)\end{array}$ & $\begin{array}{c}0.764^{* * *} \\
(0.021)\end{array}$ & $\begin{array}{c}0.783^{* * *} \\
(0.023)\end{array}$ & $\begin{array}{c}0.785^{* * *} \\
(0.023)\end{array}$ & $\begin{array}{c}0.715^{* * * *} \\
(0.025)\end{array}$ & $\begin{array}{c}0.707^{* * *} \\
(0.026)\end{array}$ & $\begin{array}{c}0.668^{* * * *} \\
(0.028)\end{array}$ & $\begin{array}{c}0.670^{* * * *} \\
(0.028)\end{array}$ \\
\hline LDR & $\begin{array}{c}0.003 \\
(0.010)\end{array}$ & $\begin{array}{l}-0.001 \\
(0.014)\end{array}$ & $\begin{array}{l}-0.026 \\
(0.016)\end{array}$ & $\begin{array}{c}-0.016 \\
(0.020)\end{array}$ & $\begin{array}{l}-0.015 \\
(0.012)\end{array}$ & $\begin{array}{c}-0.032^{* *} \\
(0.014)\end{array}$ & $\begin{array}{l}-0.005 \\
(0.014)\end{array}$ & $\begin{array}{c}0.012 \\
(0.021)\end{array}$ \\
\hline LDR $x$ female & $\begin{array}{c}0.001 \\
(0.013)\end{array}$ & $\begin{array}{l}-0.001 \\
(0.013)\end{array}$ & $\begin{array}{c}-0.023 \\
(0.021)\end{array}$ & $\begin{array}{l}-0.023 \\
(0.021)\end{array}$ & $\begin{array}{c}0.018 \\
(0.015)\end{array}$ & $\begin{array}{c}0.018 \\
(0.015)\end{array}$ & $\begin{array}{c}0.012 \\
(0.021)\end{array}$ & $\begin{array}{c}0.012 \\
(0.021)\end{array}$ \\
\hline LDR $\mathrm{x}$ probability & - & $\begin{array}{c}0.006 \\
(0.023)\end{array}$ & $\begin{array}{l}- \\
- \\
-\end{array}$ & $\begin{array}{l}-0.019 \\
(0.026)\end{array}$ & - & $\begin{array}{l}0.035 * \\
(0.021)\end{array}$ & - & $\begin{array}{c}0.013 \\
(0.027)\end{array}$ \\
\hline female & $\begin{array}{l}-0.008 \\
(0.014)\end{array}$ & $\begin{array}{c}-0.008 \\
(0.0143)\end{array}$ & $\begin{array}{l}-0.013 \\
(0.018)\end{array}$ & $\begin{array}{c}-0.013 \\
(0.018)\end{array}$ & $\begin{array}{c}0.015 \\
(0.018)\end{array}$ & $\begin{array}{c}0.015 \\
(0.018)\end{array}$ & $\begin{array}{c}-0.090^{* * *} \\
(0.026)\end{array}$ & $\begin{array}{c}-0.090^{* * *} \\
(0.026)\end{array}$ \\
\hline constant & $\begin{array}{c}0.120^{* * *} \\
(0.013)\end{array}$ & $\begin{array}{c}0.121^{* * *} \\
(0.013)\end{array}$ & $\begin{array}{c}0.081^{* * *} \\
(0.015)\end{array}$ & $\begin{array}{c}0.080^{* * *} * \\
(0.015)\end{array}$ & $\begin{array}{c}0.110^{* * *} \\
(0.018)\end{array}$ & $\begin{array}{c}0.108^{* * *} \\
(0.018)\end{array}$ & $\begin{array}{c}0.235^{* * *} \\
(0.025)\end{array}$ & $\begin{array}{c}0.234^{* * *} \\
(0.025)\end{array}$ \\
\hline Observations & 2405 & 2405 & 2534 & 2534 & 2106 & 2106 & 2268 & 2268 \\
\hline Subjects (clusters) & 185 & 185 & 181 & 181 & 162 & 162 & 162 & 162 \\
\hline$R^{2}$ within & 0.48 & 0.48 & 0.54 & 0.54 & 0.42 & 0.42 & 0.45 & 0.45 \\
\hline$R^{2}$ between & 0.01 & 0.01 & 0.02 & 0.02 & 0.01 & 0.01 & 0.09 & 0.09 \\
\hline
\end{tabular}

Standard errors in parentheses; ${ }^{*}, * *, * * *$ indicate significance at the 10,5 and $1 \%$ level respectively

$\pi_{i}$ is the normalised certainty equivalent

LDR is the right 2D:4D;2D:4Ds are entered as z-scores

female is a dummy variable with 1 for women 
Table 2: Regression analysis

\begin{tabular}{lcc}
\hline Dep. var: $\pi_{i}$ & Gains & Losses \\
\hline probability & $0.722^{* * *}$ & $0.739^{* * *}$ \\
& $(0.183)$ & $(0.016)$ \\
RDR & 0.003 & 0.003 \\
& $(0.171)$ & $(0.112)$ \\
Vietnam & $0.107^{* * *}$ & $-0.033^{* *}$ \\
& $(0.021)$ & $(0.016)$ \\
female & -0.006 & -0.007 \\
& $(0.018)$ & $(0.013)$ \\
female x Vietnam & $-0.089^{* * *}$ & 0.014 \\
& $(0.030)$ & $(0.022)$ \\
RDR x Vietnam & 0.003 & -0.012 \\
& $(0.026)$ & $(0.017)$ \\
RDR x female & -0.008 & -0.011 \\
& $(0.020)$ & $(0.014)$ \\
RDR x female x Vietnam & 0.005 & 0.030 \\
& $(0.030)$ & $(0.021)$ \\
constant & $0.106^{* * *}$ & $0.134^{* * *}$ \\
& $(0.014)$ & $(0.012)$ \\
\hline Observations & 4897 & 4537 \\
Subjects & 350 & 349 \\
$R^{2}$ within & 0.486 & 0.452 \\
$R^{2}$ between & 0.096 & 0.022 \\
\hline Standar & $* * * * *$ ind &
\end{tabular}

Standard errors in parentheses; ${ }^{*},{ }^{* *},{ }^{* * *}$ indicate significance at the 10,5 and $1 \%$ level respectively; $\pi_{i}$ is the normalised certainty equivalent; RDR is the right hand $2 \mathrm{D}: 4 \mathrm{D} ; 2 \mathrm{D}: 4 \mathrm{Ds}$ are entered as z-scores; female is a dummy variable with 1 for women.

Table 3: Regression analysis for mixed prospects in both countries

\begin{tabular}{lcc}
\hline Dep. var: GLR & Germany & Vietnam \\
\hline LDR & 0.347 & -0.035 \\
& $(0.232)$ & $(0.117)$ \\
LDR x female & -0.229 & 0.030 \\
& $(0.298)$ & $(0.251)$ \\
female & 0.042 & $0.823^{* * *}$ \\
& $(0.202)$ & $(0.252)$ \\
constant & $2.129^{* * *}$ & $1.938^{* * *}$ \\
& $(0.158)$ & $(0.144)$ \\
\hline Subjects & 188 & 162 \\
$R^{2}$ & 0.03 & 0.06 \\
\hline
\end{tabular}

Standard errors in parentheses; *, **, *** indicate significance at the 10,5 and $1 \%$ level respectively; GLR is the Gain-Loss Ratio; LDR is the left hand 2D:4D; 2D:4Ds are entered as z-scores; female is a dummy variable with 1 for women. 